\title{
Association of Benign Paroxysmal Positional Vertigo with Osteoporosis and Vitamin D Deficiency - A Case-Control Study
}

\author{
Kanwar Sen B. Vageesh Padiyar Geetu Arora \\ Department of Otorhinolaryngology and Head and Neck Surgery, Dr Ram Manohar Lohia Hospital, \\ New Delhi, India
}

\author{
Keywords \\ Vitamin D - Osteoporosis - Benign paroxysmal positional \\ vertigo $\cdot \mathrm{BPPV}$
}

\begin{abstract}
Background: Benign paroxysmal positional vertigo (BPPV) is a common type of vertigo involving the peripheral vestibular system. Consensus on the factors causing BPPV is limited. Due to the uncertainty of etiological factors causing BPPV, most cases are accepted as idiopathic. Calcium metabolism plays a primary role in the synthesis and absorption of otoconia primarily made of calcium carbonate and, thus, might be an etiological factor in the onset of BPPV. Objective: To study the role of osteoporosis and vitamin D deficiency in the etiology of BPPV. Study Design: Case-control study. Methods: This is a case-control study comparing the prevalence of osteoporosis and vitamin D deficiency in 100 patients diagnosed with idiopathic BPPV and 100 hospitalbased controls. Mean T scores and serum vitamin D levels were compared in the two groups. The groups were substratified based on age, sex, and menopausal status in order to avoid selection bias. Results: There was a high prevalence of osteoporosis and vitamin D deficiency among the patients with BPPV (60 and 76\%, respectively). Postmenopaus-
\end{abstract}

al patients with BPPV had a significantly higher prevalence of vitamin D deficiency and osteoporosis (57 and 64\%, respectively). Conclusion: The prevalence of osteoporosis and vitamin $D$ deficiency is reasonably high in the postmenopausal population. Menopausal patients with suspected BPPV may be empirically treated with vitamin D. However, other known factors causing BPPV should be investigated, and the patients should be treated accordingly.

(C) 2018 The Author(s)

Published by S. Karger AG, Basel

\section{Introduction}

Benign paroxysmal positional vertigo (BPPV) is defined as brief spells of vertigo exaggerated by the sudden act of moving to a new provoking position. It is the most common type of vertigo caused by the peripheral vestibular system. It has been reported to affect women 2 times more often than men, and it is predominantly observed in postmenopausal women [1]. There is limited knowledge related to specific factors causing BPPV. However, certain predisposing factors include old age, whiplash injuries, and viral etiology. Recently, a familial tendency has also been identified as a predisposing factor for BPPV [1]. 
Over the last 2 decades, several studies have been performed on the possible role of altered calcium metabolism in the pathogenesis of BPPV. The probable pathogenesis has been attributed to otoconia which are crystals primarily made of calcium carbonate and glycoproteins connected to the hair cells with protein fibers. A decreased absorption of calcium could be the cause of a defective synthesis of otoconia leading to the dislodgement from its original location (i.e., the macula of the utricle and saccule) into the semicircular canals or cupula, thereby causing canalolithiasis or cupulolithiasis, respectively.

Vitamin D, on the other hand, is known to maintain calcium hemostasis by increasing its absorption from the intestines. Several studies have indicated a high prevalence of osteoporosis in patients with BPPV. However, the relationship between BPPV and osteoporosis is debatable.

The objective of this study was to observe the prevalence of vitamin D deficiency and osteoporosis in patients with BPPV and in a control population.

\section{Patients and Methods}

This case-control study was performed between August 2014 and December 2017 at the Department of Otorhinolaryngology in collaboration with the Department of Orthopedics, Dr Ram Manohar Lohia Hospital, New Delhi, India. A total of 100 patients, of either sex, between 18 and 60 years, and diagnosed with idiopathic BPPV, were included in this study. Additionally, 100 healthy subjects who opted to be screened for osteoporosis and vitamin D deficiency were included as controls. The study design was reviewed by the institutions Ethics Committee (File No-1-40/ 13/2014/IEC/Thesis/PGIMER/RMLH/1457). Oral and written informed consent regarding the aim, study design, and clinical implications of this study was obtained from all participants.

All cases primarily underwent neurotological examination and audiological assessment by a single senior otologist. The Dix-Hallpike maneuver, a supine roll (Pagnini-McClure maneuver), and cephalic hyperextension were conducted to identify a possible involvement of the semicircular canal (SCC). Patients with BPPV involving the posterior SCC were treated with the Epleys maneuver, while those with involvement of the lateral and superior SCC were treated with barbeque rotation and Yacovino maneuver, respectively.

Both case and control groups underwent serum 25-OH vitamin D estimation and bone mass density assessment using chemiluminescence immunoassay and dual-energy X-ray absorptiometry, respectively. A lowest $\mathrm{T}$ score $<-2.5$ from the lumbar and femoral areas was regarded as osteoporosis.

\section{Statistical Analysis}

Mean T scores and mean serum 25-OH vitamin D levels were compared, and the prevalence of vitamin D deficiency for the case and control groups was calculated. The groups were subdivided according to age ( $<45$ years and $>45$ years), sex, and menopausal status (pre- and postmenopausal).

Benign Paroxysmal Positional Vertigo, Osteoporosis, and Vitamin D Deficiency
Table 1. Patient demographics and characteristics

\begin{tabular}{|c|c|c|c|}
\hline & Cases & Controls & $p$ value \\
\hline \multicolumn{4}{|l|}{ Age } \\
\hline Mean $\pm S D$, years & $48.6 \pm 10.2$ & $46.2 \pm 10.6$ & 0.432 \\
\hline Median (range), years & $50.2(18-60)$ & $52.6(18-60)$ & \\
\hline$<45$ years & $42(42 \%)$ & $38(38 \%)$ & 0.348 \\
\hline$>45$ years & $58(58 \%)$ & $62(62 \%)$ & \\
\hline \multicolumn{4}{|l|}{ Sex } \\
\hline Male & $32(32 \%)$ & $42(42 \%)$ & 0.621 \\
\hline Female & $68(68 \%)$ & $58(58 \%)$ & \\
\hline \multicolumn{4}{|l|}{ Menopausal status } \\
\hline Premenopausal & $24(35 \%)$ & $22(38 \%)$ & 0.423 \\
\hline Postmenopausal & $44(65 \%)$ & $36(62 \%)$ & \\
\hline
\end{tabular}

Mean $( \pm S D)$, median, range, and ratio values were used for an analytical description of the data. The distribution of variables was analyzed using the Kolmogorov-Smirnov test. The Fisher test and the $\chi^{2}$ test were used for the analysis of qualitative data, while the Mann-Whitney $\mathrm{U}$ test and the independent $t$ test were used for quantitative data analysis. Statistical package for social services (SPSS) version 22.0 was used for the statistical analysis. A $p$ value $<0.05$ was considered to be statistically significant.

\section{Results}

The mean age of all 200 subjects was 48.35 years (range 18-60). Of these, 134 were female (67\%) and 66 were male (33\%). The mean age of all males was $48.8 \pm 11.1$, while that of all females was $55.5 \pm 4.0$. The mean serum $25-\mathrm{OH}$ vitamin D level of all participants was $15.8 \mathrm{ng} / \mathrm{mL}$ (range 8-60, mean \pm SD $14.28 \pm 4.8 \mathrm{ng} / \mathrm{mL}$ ). The mean serum $25-\mathrm{OH}$ vitamin $\mathrm{D}$ concentration in males was $16.18 \pm 5.22$, while that of females was $12.28 \pm 5.46 \mathrm{ng} / \mathrm{mL}$. In our study, in the patients diagnosed with BPPV, the posterior SCC was most commonly involved $(n=78)$, followed by the lateral SCC $(n=16)$, and the superior SCC $(n=4)$. An involvement of both the posterior and lateral SCC was noticed in 2 cases $(n=2)$. No significant correlation was observed between mean age and sex distribution in the cases and controls ( $p=0.348$ and $p=0.621$, respectively) (Table 1$)$.

\section{T Scores}

The mean T score of the patients with BPPV and that of the control group were $-2.6 \pm 1.2$ and $-1.8 \pm 1.1$, respectively. The prevalence of osteoporosis in the BPPV group and the control group was 60 and $22 \%$, respectively. A significant difference in the mean $\mathrm{T}$ scores and the prevalence of osteoporosis between the two groups was 
Table 2. T score, osteoporosis, and vitamin $\mathrm{D}$ deficiency among the cases versus controls

\begin{tabular}{llll}
\hline & Cases & Controls & $p$ value \\
\hline Mean T score \pm SD & $-2.6 \pm 1.2$ & $-1.8 \pm 1.1$ & 0.032 \\
Osteoporosis, $n(\%)$ & & & 0.044 \\
$\quad$ Yes & $60(60)$ & $22(22)$ & \\
$\quad$ No & $40(40)$ & $78(78)$ & \\
Mean vitamin D level \pm SD & $20.3 \pm 12.2$ & $18 \pm 10.1$ & 0.041 \\
Deficiency, $n(\%)$ & & & 0.02 \\
$\quad$ Yes & $76(76)$ & $42(42)$ & \\
$\quad$ No & $24(24)$ & $58(58)$ & \\
\hline
\end{tabular}

noted ( $p=0.032$ and $p=0.044)$. The mean T scores in the premenopausal BPPV patients and the premenopausal control group were $-2.3 \pm 1.3$ and $1.5 \pm 2.3$, respectively. The prevalence of osteoporosis in the premenopausal BPPV patients and the controls was 68 and 32\%, respectively. The mean $\mathrm{T}$ scores in the postmenopausal BPPV patients and the control group were $-2.6 \pm 1.6$ and $-2.2 \pm$ 1.2 , respectively. The prevalence of osteoporosis in the postmenopausal BPPV patients and the postmenopausal control patients was 71 and $41 \%$, respectively. There was a significant difference in the mean $\mathrm{T}$ scores and the prevalence of osteoporosis between the premenopausal and postmenopausal groups $(p=0.043, p=0.049, p=0.021$, and $p=0.05$, respectively) (Table 2 ).

\section{Serum 25-OH Vitamin D Levels}

The mean serum 25-OH vitamin D levels in the BPPV patients and controls were $20.3 \pm 12.2$ and $18 \pm 10.1 \mathrm{ng} /$ $\mathrm{mL}$, respectively. The prevalence of vitamin $\mathrm{D}$ deficiency among the cases and controls was 76 and $42 \%$, respectively. A significant difference was observed in the mean serum $25-\mathrm{OH}$ vitamin $\mathrm{D}$ level and the deficiency prevalence between the two groups ( $p=0.041, p=0.02$, respectively).

The mean serum $25-\mathrm{OH}$ vitamin D levels in the premenopausal BPPV patients and the controls were $20 \pm$ 4.8 and $30.9 \pm 8.5 \mathrm{ng} / \mathrm{mL}$, respectively. The prevalence of vitamin D deficiency in the two groups was 46 and 14\%, respectively. There was a significant difference in the mean serum $25-\mathrm{OH}$ vitamin $\mathrm{D}$ level and the deficiency prevalence between the two groups $(p=0.002, p=0.004$, respectively). The control group had a higher serum 25$\mathrm{OH}$ vitamin $\mathrm{D}$ level and a lower vitamin $\mathrm{D}$ deficiency than the premenopausal BPPV group.

However, in this study, we observed a significant difference between the postmenopausal BPPV patients and
Table 3. T score, osteoporosis, and vitamin D deficiency in the premenopausal and postmenopausal group (cases vs. controls)

\begin{tabular}{|c|c|c|c|}
\hline & Cases & Controls & $p$ value \\
\hline \multicolumn{4}{|l|}{ Premenopausal group } \\
\hline Mean T score \pm SD & $-2.3 \pm 1.3$ & $-1.5 \pm 1.3$ & 0.043 \\
\hline Osteoporosis, $n(\%)$ & & & 0.049 \\
\hline Yes & $17(71)$ & $9(41)$ & \\
\hline No & $7(24)$ & $13(59)$ & \\
\hline Mean vitamin $\mathrm{D}$ levels $\pm \mathrm{SD}$ & $20 \pm 4.8$ & $30.9 \pm 8.5$ & 0.021 \\
\hline Deficiency, $n(\%)$ & & & 0.042 \\
\hline Yes & $11(46)$ & $3(14)$ & \\
\hline No & $13(54)$ & $19(86)$ & \\
\hline \multicolumn{4}{|l|}{ Postmenopausal group } \\
\hline Mean T score \pm SD & $-2.6 \pm 1.6$ & $-2.2 \pm 1.2$ & 0.021 \\
\hline Osteoporosis, $n(\%)$ & & & 0.051 \\
\hline Yes & $28(64)$ & $11(31)$ & \\
\hline No & $16(36)$ & $25(69)$ & \\
\hline Mean vitamin D levels $\pm \mathrm{SD}$ & $22.2 \pm 12.3$ & $18.5 \pm 8.2$ & 0.082 \\
\hline Deficiency, $n(\%)$ & & & 0.231 \\
\hline Yes & $25(57)$ & $17(47)$ & \\
\hline No & $19(43)$ & $19(53)$ & \\
\hline
\end{tabular}

the postmenopausal control group $(p=0.082, p=0.231$, respectively) (Table 3).

\section{Discussion}

The formation and maintenance of otoconia require an inflow of calcium from the epithelial cells of the utricle and saccule into cells through $\mathrm{Ca}^{2+}$-selective transient receptor potential vanilloid (TRPV) 5-TRPV 6 channels [2]. The subsequent combination of $\mathrm{Ca}^{2+}$ with $\mathrm{Ca}$ buffer protein calbindin-D9K and calbindin-D28K and the release of $\mathrm{HCO}_{3}{ }^{-}$from carbonic anhydrase cause high levels of $\mathrm{Ca}^{2+}$ and $\mathrm{HCO}_{3}{ }^{-}$in the endolymph to form $\mathrm{CaCO}_{3}$ vitreous bodies. Through the actions of membranebound proteins, such as NADPH oxidases (Nox3) and otopetrin-1, the $\mathrm{CaCO}_{3}$ vitreous bodies get converted into otoconia which matures and anchors to the otolithic membrane [2]. Some animal experiments in rats have shown the degeneration of otoconia and linking filaments which increases with age suggesting an age-related mechanism [3].

In our study, we observed a higher prevalence of osteoporosis in postmenopausal patients with BPPV (64\%). A similar observation was reported by Vibert et al. [4] in a case-control studies of 32 females with BPPV. Possible explanations for this mechanism by the authors 
were (a) a decrease in estrogen caused a reduction in the natural regulation of bone, causing changes in the internal structure of otoconia and its attachments to the gelatinous matrix, and (b) a reduced capacity to dissolve dislodged otoconia due to an increase in free calcium in the endolymph followed an increased calcium resorption [4].

A similar observation was made by Jeong et al. [5] who reported higher ratios of osteopenia and osteoporosis in both female and male patients with BPPV. Another study by Yamanaka et al. [6] reported a higher incidence of BPPV recurrence $(56.3 \%)$ in premenopausal woman aged $\geq 50$ years compared to postmenopausal patients with normal bone density (16.1\%). The risk of recurrence further increased when patients had two or more underlying comorbidities, such as hypertension, diabetes, or osteoarthrosis [7]. Buki et al. [8] reported that patients who were on vitamin $\mathrm{D}$ supplementation therapy showed no additional recurrence of BPPV.

\section{Conclusion}

Our observation suggests that osteoporosis and vitamin D deficiency are both dependent factors for idiopathic BPPV. Investigative work-up for patients with idiopathic BPPV should be done to rule out an autoimmune pathology, vasculitis, trauma, or a systemic illness. Patients presenting with recurrent refractory BPPV should be screened for both osteoporosis and vitamin D deficiency.

\section{Statement of Ethics}

The authors confirm that all the subjects have given their written informed consent and that the study protocol has been approved by the research institutes Ethics Committee. The study was conducted in accordance with the World Medical Association Declaration of Helsinki.

\section{Disclosure Statement}

The authors have no conflicts of interest to declare.

\section{References}

1 Karataș A, Acar Yüceant G, Yüce T, Hacı C, Taylan Cebi I, Salviz M: Association of benign paroxysmal positional vertigo with osteoporosis and vitamin $\mathrm{D}$ deficiency: a case controlled study. J Int Adv Otol 2017;13:259-265.

2 Rhim GI: Serum vitamin D and recurrent benign paroxysmal positional vertigo. Laryngoscope Investig Otolaryngol 2016;1:150-153.

3 Jang YS, Hwang CH, Shin JY, Bae WY, Kim LS: Age-related changes on the morphology of the otoconia. Laryngoscope 2006;116:9961001.
4 Vibert D, Kompis M, Hausler R: Benign paroxysmal positional vertigo in older women may be related to osteoporosis and osteopenia. Ann Otol Rhinol Laryngol 2003;112:885889.

5 Jeong SH, Kim JS, Shin JW, Kim S, Lee H, Lee AY, Kim JM, Jo H, Song J, Ghim Y: Decreased serum vitamin $\mathrm{D}$ in idiopathic benign paroxysmal positional vertigo. J Neurol 2013;260: 832-838.

6 Yamanaka T, Shirota S, Sawai Y, Murai T, Fujita N, Hosoi H: Osteoporosis as a risk factor for the recurrence of benign paroxysmal positional vertigo. Laryngoscope 2013;123: 2813-2816.
7 De Stefano A, Dispenza F, Suarez H, PerezFernandez N, Manrique-Huarte R, Ban JH, Kim MB, Strupp M, Feil K, Oliveira CA, Sampaio AL, Araujo MF, Bahmad F Jr, Ganança MM, Ganança FF, Dorigueto R, Lee H, Kulmarva G, Mathur N, Di Giovanni P, Petrucci AG, Staniscia T, Citraro L, Croce A: A multicenter observational study on the role of comorbidities in the recurrent episodes of benign paroxysmal positional vertigo. Auris $\mathrm{Na}$ sus Larynx 2013;41:31-36.

8 Buki B, Ecker M, Junger H, Lundberg YW: Vitamin D deficiency and benign paroxysmal positioning vertigo. Eur Arch Otorhinolaryngol 2013;80:201-204. 